\title{
Elimination of Lubricants from Aluminum Cold Rolled Products Using Short Laser Pulses
}

\author{
M.S.F. Lima ${ }^{a}{ }^{*}$, J.-D. Wagnière ${ }^{a}$, S.P. Morato ${ }^{b}$, N.D. Vieira Jr. ${ }^{c}$ \\ ${ }^{a}$ Center for Laser Treatment of Materials, Swiss Federal Institute of Technology Lausanne, \\ C. P. 110, CH-1015 Lausanne, Switzerland. \\ ${ }^{b}$ LaserTools Technology Ltd. \\ C. P. 11049, 05422-970 Sao Paulo - SP, Brazil \\ ${ }^{c}$ Center for Lasers and Applications \\ C. P. 11049, 05422-970 Sao Paulo - SP, Brazil
}

Received: February 6, 2002; Revised: April 24, 2002

\begin{abstract}
This work presents a new technique to remove the surface impurities from the aluminum coldworked sheets. The method consists to concentrate a short-time high-power pulsed laser on the materials surface and scan it in order to cover a desired area. Incrustations ablation is obtained as long as the fluency and the peak power are high enough to produce vaporization of the contaminated layer without affecting the material surface properties. The present problem consists in eliminating a desiccated soap of about $1 \mathrm{~g} / \mathrm{m}^{2}$ from the surface of a 6016-class aluminum alloy sheet. The soap is originated from the rolling process. The present laser method is intended to replace water washing when the piece cannot be soaked, when drying is difficult due to the geometry, or when environmental restrictions apply. Best results were obtained when the pulse length was $100 \mathrm{~ns}$ and the average laser power was $95 \mathrm{~W}$. In these conditions, the surface was completely cleaned and the aluminum alloy did not suffer any structural modification.
\end{abstract}

Keywords: laser cleaning, laser ablation, aluminum alloys

\section{Introduction}

Laser technology has attracted considerable interest for the cleaning of materials when conventional methods present unsatisfactory or costly results. This is the case of artwork restoration where lasers can be used to eliminate oxides, dirt, paint and mosses in a very controlled manner ${ }^{1}$. Lasers have been used also in microelectronics ${ }^{2,3}$ and metallurgy $y^{4,5}$ to clean surfaces with or without surface modification.

Two processes can achieve laser cleaning: athermal and thermal ablation. Athermal processing is obtained when the surface incrustation is fragmented and ejected due to a mechanical shock wave. This effect is usually controlled by the energy density: low values are ineffective and high values lead to substrate damage. In order to drive shockwave ablation, pulse lengths in the range of picoseconds up to some few nanoseconds should be produced ${ }^{6-9}$. On the other hand, thermal ablation is obtained for longer pulse lengths ${ }^{10,11}$. The volatilization of a surface layer is due to the rapid conversion of the laser energy in latent heat of vaporization. The former practice has two advantages:

a) The process window, i.e. the set of variables to produce cleaning is larger than in the case of athermal process. The same laser workstation can be used to process a variety of materials.

b) The laser workstation has a relative low cost and can be also used for marking and engraving thus conferring versatility.

These facts motive for the use of a flexible workstation with pulse lengths of some hundreds of nanoseconds and an energy per pulse of less than one joule.

In the present case, it is intended to use the pulsed laser power to clean aluminum surfaces which are contaminated with a saponaceous solution. The solution is the ALUB ZX ${ }^{12}$ dry lubricant used for the cold rolling of aluminum alloys. This product minimizes staining and provides excellent lubrication. The aluminum sheets are utilized in the construc- 
tion of blanks for automobiles after assembly by TIG welding. The problem of cleaning appeared when it was noticed that bobles were present in the welding. These bobbles were associated to a volatile surface contaminant, which is originated from the lubricant.

The objective of the present contribution is to determine the best conditions for laser cleaning of the aluminum sheets, where: surface contamination is eliminated and the substrate material is not modified. The final goals are to reduce defects in welding and to eliminate the emission of aqueous pollutants.

\section{Experimental}

Cold rolled aluminum sheets of 2-mm thick were produced in the Alusuisse Swiss Aluminum Ltd. at Chippis, Switzerland. The alloy is a high-strength AA6016 in the T4 condition before rolling. One milligram per square meter of the dry lubricant ALUB ZX is applied at each surface in order to enhance conformation and reduce stain. The lubricant consists of natural and synthetic esters, fatty alcohols, glycols, non-ionic surfactants, soap and water. Once dried out the residues look like a chalky layer of soap. This lubricant has a partial solubility in water and complete removal is possible by manual operation or in an ultrasonic bath of alcohol. The biological accumulation leads to a partial alkalization of the ecosystem, thus waste products should be treated with ultra-filtration or inverse osmosis systems ${ }^{13}$.

The laser workstation consisted of a F94S, Q-Switched Nd:YAG lamp pumped laser from FOBA with a galvanometric scanning head to direct the beam in the $x y$ plane. The Nd:YAG laser has a maximum average power of $95 \mathrm{~W}$ and can be operated in continuous wavelength $(\mathrm{CW})$ or in Q-switched mode. The lamp current controls the laser output power in the range 10-95 W. The pulse length, in the range $100-1000 \mathrm{~ns}$, and the frequency, in the range $1-30 \mathrm{kHz}$, are correlated. The energy per pulse is the ratio of the average power to the frequency.

The laser ablation produces a dense cloud of hot vapors and debris that will condense and recontaminate the surface if not removed immediately. Contamination could be prevented by entrainment into a flowing gas stream or by an air suction system. Both methods are effective if the metallic surface remains unmelted. In the present case, it was used an industrial aspiration system.

The scanning head had two independent mirrors mounted on galvos which allows a xy scan of the laser beam over a surface of $10 \times 10 \mathrm{~cm}^{2}$ at speeds up to $400 \mathrm{~mm} / \mathrm{s}$. The treatment zone, which is restricted to $1 \mathrm{~cm}^{2}$ in the present study, was obtained by a partial superposition of parallel tracks.

The microstructural analyses were carried out using a Scanning Electron Microscope Cambridge S-360 with a $\mathrm{LaB}_{6}$ anode and spatial resolution of $4-\mathrm{nm}$ at $30 \mathrm{kV}$.

\section{Results and discussion}

The process parameters in laser processing are interconnected. The lamp current in the laser cavity controls the average output power $(\overline{\mathrm{P}})$. This later controls three other variables: the energy per pulse $(\mathrm{E})$, the pulsing frequency (f), and the temporal pulse length $\left(\mathrm{t}_{\mathrm{p}}\right)$. For the maximum average power of $95 \mathrm{~W}$, for instance, one can set the frequency at $1 \mathrm{kHz}$, but the values of energy and pulse length are fixed as $0.095 \mathrm{~J}(\overline{\mathrm{P}}=\mathrm{E} . \mathrm{f})$ and $100 \mathrm{~ns}$, respectively. The focusing device (a f-theta lens) also controls the beam spot diameter (D) via the focusing distance. For a single shot, the fluency $(\mathrm{F})$ is the ratio of the pulse energy by the irradiated area. However, the motion of the beam over the material surface implies in a partial superposition of individual laser shots. For a linear scanning speed $\mathrm{V}_{\mathrm{b}}$ the overlapping times is:

$$
\mathrm{N}=\frac{\mathrm{D} \cdot \mathrm{f}}{\mathrm{V}_{\mathrm{b}}} \quad(-)
$$

The fluency can be expressed as the sum of the energy of each laser shot when the beam travel a distance of the beam spot diameter:

$$
\mathrm{F}=\frac{\mathrm{N} \cdot \overline{\mathrm{P}}}{\text { A.f }} \quad\left(\mathrm{J} \cdot \mathrm{m}^{-2}\right)
$$

Substituting the terms of Eq. 1, considering the area as a function of spot diameter and adding a term $\beta$, the fraction of energy absorbed by the surface, one obtains:

$$
\mathrm{F}=\frac{4}{\pi} \frac{\beta \cdot \overline{\mathrm{P}}}{\mathrm{D} \cdot \mathrm{V}_{\mathrm{b}}} \quad\left(\mathrm{J} \cdot \mathrm{m}^{-2}\right)
$$

Another important parameter is the peak power, $\mathrm{P}_{\mathrm{p}}$, which is:

$$
\mathrm{P}_{\mathrm{p}}=\frac{\beta \cdot \overline{\mathrm{P}}}{\mathrm{t}_{\mathrm{p}} \cdot \mathrm{f}}
$$

Both fluency and peak power were varied in the present work in order to produce a process chart. For this, the scanning velocity and the beam spot diameter must be fixed. The velocity was fixed at an intermediary value $\left(\mathrm{V}_{\mathrm{b}}=100 \mathrm{~mm} / \mathrm{s}\right)$, giving $\mathrm{N}$ between 4.8 and 72 for frequencies between 1 and $15 \mathrm{kHz}$. The beam diameter was 420 $\mu \mathrm{m}$ at focus, and increased to about $480 \mu \mathrm{m}$ when defocused by $-20 \mathrm{~mm}$ or $+20 \mathrm{~mm}$. The best cleaning effect was obtained when the focus was in the sample at $-20 \mathrm{~mm}$. Therefore, considering $\beta=1$ (total absorption in the layer), the fluency at $\bar{P}=95 \mathrm{~W}$ is $2.5 \mathrm{~J} / \mathrm{mm}^{2}$. However, this value should be something lower because the overlapping shots $(\mathrm{N})$ do not supply the same heat at every position and because the laser absorption in the incrustation is not complete $(\beta<1)$.

A processing chart was then constructed by changing the current lamp and the frequency, (Fig. 1). The black square 


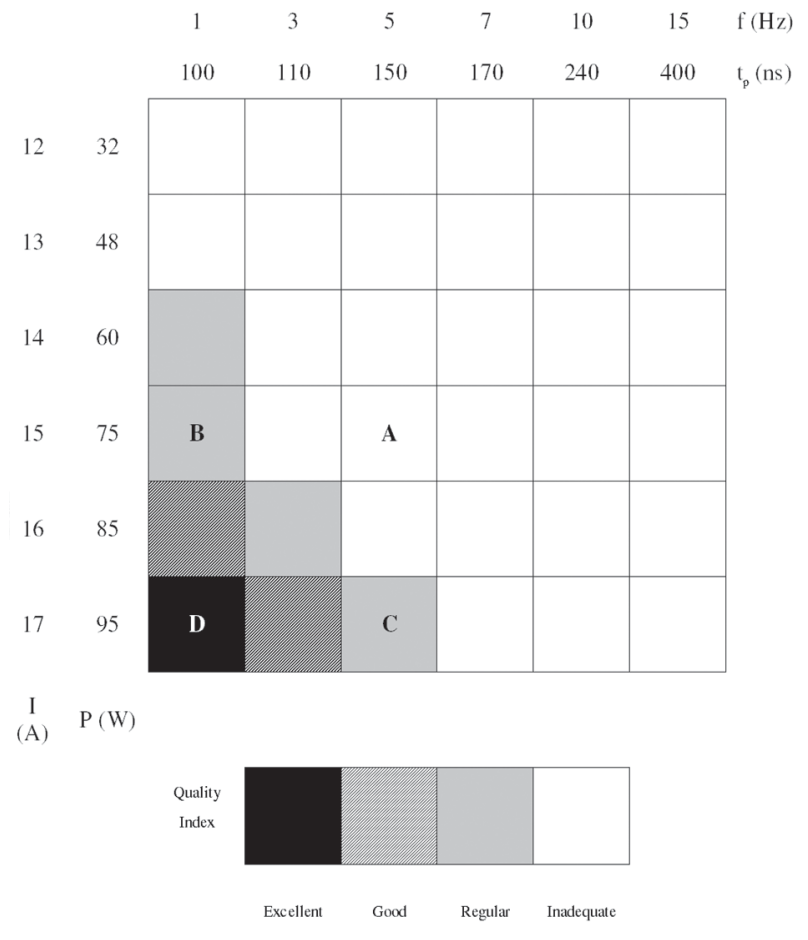

Figure 1. Process chart for the laser cleaning of aluminum sheets. Letters refer to the micrographs in Fig. 2.

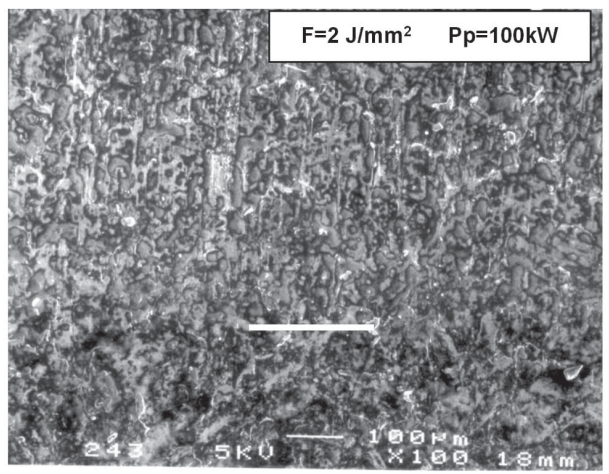

(A)

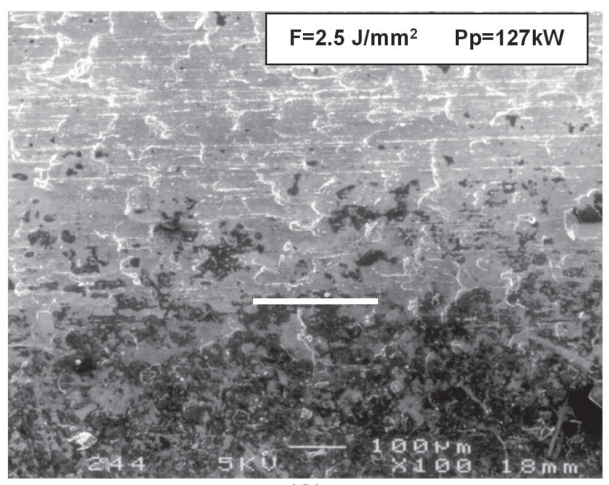

(C) represents the condition where the surface was completely cleaned. Dashed squares represent good results, i.e. most of surface was uncontaminated but some spots remain. Grey squares indicate surfaces with various points and plates of incrustations. Finally, white squares represent surfaces where the cleaning did not occur. The scanning electron micrographs of four representative cases were presented in Fig. 2.

The best result was obtained when the laser parameters were set-up to give $2.5 \mathrm{~J} / \mathrm{mm}^{2}$ and $950 \mathrm{~kW}$. These results indicate that both fluency and peak power are important factors in the cleaning mechanism.

Literature results ${ }^{4,14}$ indicate that the fluency level (2$2.5 \mathrm{~J} / \mathrm{mm}^{2}$ ) and pulse length are pertinent to a process of ablation based in heterogeneous nucleation of vapor bobbles with consequent fragmentation. Thus thermal transfer to the incrustation mainly controls the process. This transfer only slight changes the topography of the sheet, Fig. 2, and must not affect the macroscopic material properties. Additionally considering that these regions are going to be welded after cleaning, the small roughness increases the absorptivity when laser weld is employed.

Since the displacement of the laser beam is fully automated, it is possible to integrate the cleaning solution directly in the welding head. Some preliminary tests of

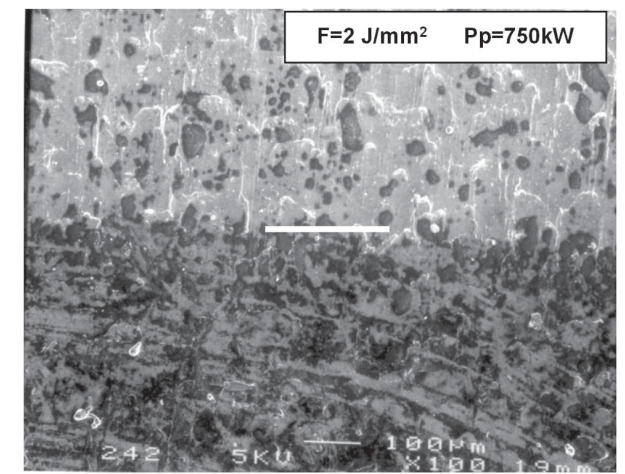

(B)

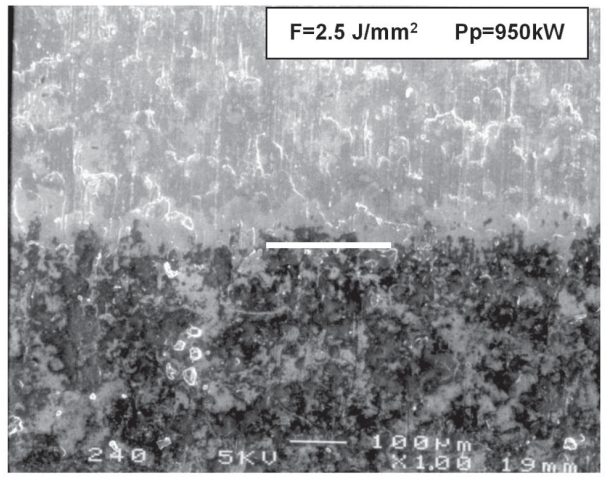

(D)

Figure 2. Scanning electron micrographs at the boarder of the irradiated zones showing the effect of laser parameters on the effectiveness of cleaning. White lines indicate untreated and treated regions, corresponding to the lower and the upper regions, respectively. The rectangles give information on the fluency and peak power for each experiment. The letters point to conditions in the processing chart of Fig. 1 . 
weldability of laser cleaned AA6016 sheets have shown excellent results ${ }^{15}$.

\section{Conclusions}

This work presents an alternative technique to clean surfaces of aluminum cold rolled products based on the laser technology. For the specific case of an ALUB ZX contaminant on a AA6016 it had been show that the surfaces can be conveniently cleaned using $2.5 \mathrm{~J} / \mathrm{mm}^{2}$ fluency and a peak power of $950 \mathrm{~kW}$. The results were summarized in a process chart (Fig. 1) and in the micrographs showing different laser parameters (Fig. 2). The combination of laser cleaning and laser welding is also proposed as a way to increase weldability in these alloys.

\section{Acknowledgements}

This work is funded by FAPESP (Fundação de Amparo à Pesquisa do Estado de São Paulo, Brazil) under grants 01/ 04159-7 and 98/07319-0 and by Swiss Federal Institute of Technology, Lausanne, Switzerland.

\section{References}

1. Drollette, D. Photonics Spectra, March, pp. 90-98, 2001.

2. Illyefalvi-Vitez, Z., Microelectronics Reliability, v. 41, p. 563-570, 2001.

3. Ozono, K.; Obara, M.; Usui, A.; Sunakawa, H. Optics Communications, v. 189, p. 103-106, 2001.
4. Song, K.H.; Xu, X. Applied Surface Science, v. 127-129, p. 111-116, 1998.

5. Coddet, C.; Montavon, G.; Ayrault-Costil, S.; Freneaux, O.; Rigolet, F.; Barbezat, G.; Folio, F.; Diard, A.; Wazen, P. J. Thermal Spray Tech., v. 8, p. 213, 1999.

6. Chen, J.P.; Ni, X.W.; Lu, J.; Bian, B.M. Optics Coтmunications, v. 176, p. 437-440, 2000.

7. Jeong, S.H.; Greif, R.; Russo, R.E. Applied Surface Science, v. 127-129, p. 1029-1034, 1998.

8. Stauter, C.; Fontaine, J.; Engel, Th. Applied Surface Science, v. 96-98, p. 522-527, 1996.

9. Psyllaki, P.; Oltra, R. Materials Science and Engineering, v. A282, p. 145-152, 2000.

10. Zhou, X.; Imasaki, K.; Furukawa, H.; Umino, H.; Sakagishi, K.; Nakai, S.; Yamanaka, C. Optics and Laser Technology, v. 33, p. 189-194, 2001.

11. Lima, M.S.F.; Vieira, N.D.; Morato, S.P.; Vencovsky, P. accepted Materials Science and Engineering A, 2001.

12. ALUB ZX is a product and a trademark of Alusuisse Aluminium of Switzerland Ltd.

13. ALUB ZX technical data worksheet, Alusuisse Aluminium of Switzerland Ltd., 1998.

14. Sobol, E.N. Phase Transformations and Ablation in Laser-treated Solids, John Wiley and Sons, USA, p. 75, 1995.

15. Kurz, W.; Lima, M.S.F.; Wagniere, J.D.; Rappaz, M. Welding process, patent number 01810986.8-1262, European Patent Office, 09/10/2001 (date of filing). 